\title{
VHF and UHF Signal Characteristics Observed on a Long Knife-Edge Diffraction Path
}

\author{
A. P. Barsis and R. S. Kirby
}

(Received April 6, 1961)

Contribution from Central Radio Propagation Laboratory, National Bureau of Standards, Boulder, Colo.

During 1959 and 1960 long-term transmission loss measurements were performed over a 223 kilometer path in Eastern Colorado using frequencies of 100 and 751 megacycles per second. This path intersects Pikes Peak which forms a knife-edge type obstacle visible from both terminals. The transmission loss measurements have been analyzed in terms of diurnal and seasonal variations in hourly medians and in instantaneous levels. As expected, results show that the long-term fading range is substantially less than expected for tropospheric scatter paths of comparable length. Transmission loss levels were in general agreement with predicted knife-edge diffraction propagation when allowance is made for rounding of the knife edge. A technique for estimating long-term fading ranges is presented and the results are in good agreement with observations. Short-term variations in some cases resemble the space-wave fadeouts commonly observed on within-the-horizon paths, although other phenomena may contribute to the fading. Since the foreground terrain was rough, there was no evidence of direct and ground-reflected lobe structure.

In most cases comparatively high correlation exists between signals received simultaneously on two antennas with 8.3 and 14 meters vertical separation. These separations were chosen as being representative for practical space diversity systems designed for eliminating the effects of fading arising from direct and ground-reflected phase interference phenomena. The comparatively high correlation observed suggests that space diversity will be relatively less successful in mountain obstacle paths with rough terrain near the terminals than on tropospheric scatter paths or on line-of-sight paths over smooth terrain.

The enhancement of field strength associated with propagation over mountain ridges may cause concern in applications where mountains are being counted on to shield unwanted radio waves. Some radio astronomy installations have been located in mountain valleys for this reason, and it is possible that obstacle-gain effects may aggravate rather than alleviate interference.

\section{Introduction}

It is generally known that mountain ridges can act as diffracting knife-edges in point-to-point communication circuits on VHF and UHF frequencies. The mathematical approach has been developed using the Fresnel-Kirchhoff diffraction theory [Schelleng, Burrows, and Ferrell, 1933]. Substantial reductions in transmission loss as compared to scatter circuits of similar length, and relatively fading-free signals were reported by several workers, both in this country and abroad [Dickson, Egli, Herbstreit, and Wickizer, 1953; Kirby, Dougherty, and McQuate, 1955; Kono and Hirai, 1955; Crysdale, Day, Cook, Psutka, and Robillard, 1957; Nishikori, Kurihara, Fukushima, and Ikeda, 1957; Hirai, Fujii and Saito, 1958]. More recently, additional work in Japan [Kakita, Iwai, and Ieiri, 1959], and so far unpublished data from Alaskan knife-edge diffraction paths ${ }^{1}$ have shown that some paths exhibit considerable fading at carrier frequencies in the $900 \mathrm{Mc} / \mathrm{s}$ range. Much of the time the fading encountered resembles the "space-wave fadeout" phenomena observed commonly on withinthe-horizon paths at comparable frequencies [Bean, 1954]. It consists of relatively deep and slow fades, and the occurrence of these fades may show marked

${ }_{1}^{1}$ Private communication from Western Electric Co. diurnal trends and correlation with meteorological phenomena as well as with simultaneous ducting on paths just beyond the horizon.

To obtain a better understanding of the long-term signal and fading characteristics, NBS established a test path in Colorado to study knife-edge type diffraction phenomena. This path extends in a roughly north-south direction along the Front Range of the Colorado Rockies, and uses Pikes Peak as the diffracting knife-edge. An outline map of the path with the locations of the terminals at Beulah and Table Mesa, Colo., is shown on figure 1. Pertinent path and equipment data are given in table 1, below. The path profile is shown on figure 2 , based on an equivalent earth radius of $9,000 \mathrm{~km}$. This is 1.41 times the actual earth's radius and corresponds to a surface refractivity of $316 \mathrm{~N}$-units.

Operation on $751 \mathrm{Mc} / \mathrm{s}$ commenced in December 1959, and terminated in September 1960. Data were recorded continuously during 5-day periods at the rate of one each month with more frequent operation in June and August. Operation on $100 \mathrm{Mc} / \mathrm{s}$ started in August 1960, on the same basis. During two 5-day periods in August 1960, an additional site was operated on top of Pikes Peak, using horizontal half-wave dipole receiving antennas on both frequencies. These antennas were mounted about $6 \mathrm{~m}$ above ground. The length of this auxiliary line-of-sight path was $77 \mathrm{~km}$. 


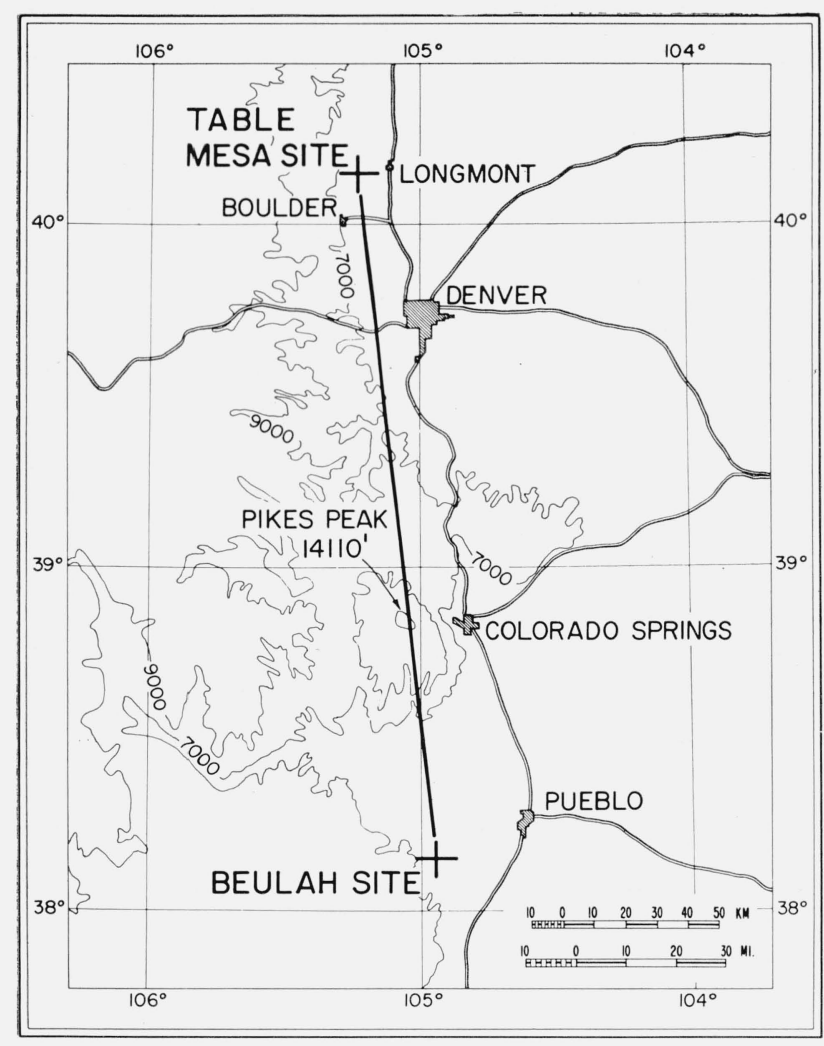

Figure 1. Outline map for Colorado obstacle gain path.

TABLE 1. Path and equipment data

Pikes Peak obstacle gain poth

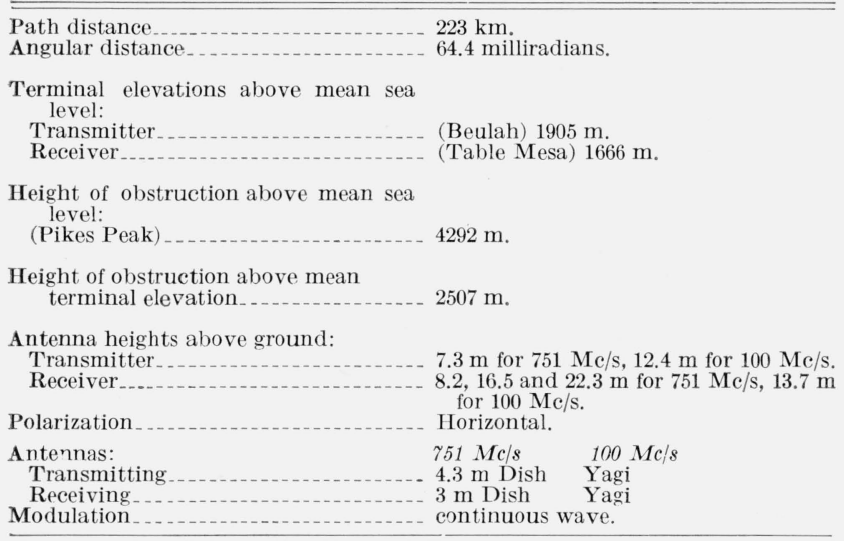

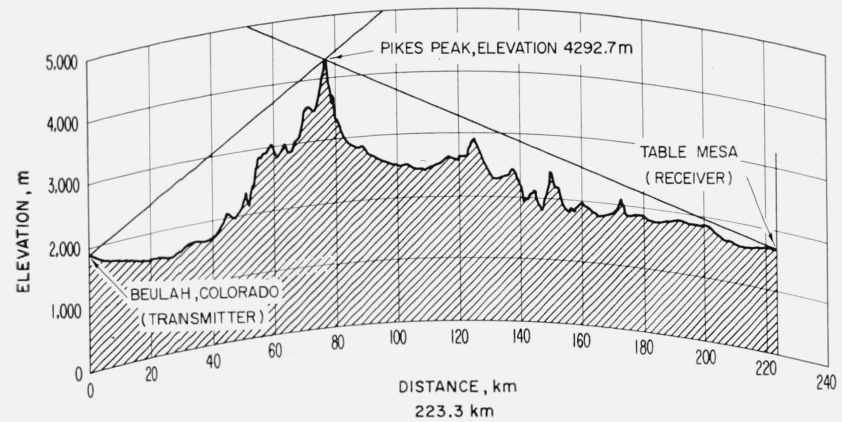

FIGURE 2. Terrain_profile of Colorado obstacle gain propagation path.
The receiver outputs were recorded on strip charts and multichannel magnetic tape. Transmitter power output values were also recorded on strip charts, so that a continuous record of the transmitter power is available for both frequencies. The receivers were calibrated by signal generators checked against laboratory standards.

\section{Characteristics of the Received Signal and Variation of Hourly Median Values}

\subsection{Signal Characteristics}

Figure 3 shows sample recordings of both frequencies at the two sites taken on the morning of August 10,1960 . The $751 \mathrm{Mc} / \mathrm{s}$ record at the Table Mesa receiving site shows more rapid small signal variations superimposed on a much slower fading pattern, which includes a fade in excess of $15 \mathrm{db}$ lasting several minutes. There appears to be substantial correlation between the signal recorded simultaneously on the two antennas on $751 \mathrm{mc} / \mathrm{s}$. The slow fading pattern is absent on the Table Mesa $100 \mathrm{Mc} / \mathrm{s}$ record; only the more rapid variations are present, and they are superimposed on a virtually constant signal. It is believed that these rapid signal variations of small amplitude are due to a component of scattered field superimposed on the more slowly varying diffracted field. For the lineof-sight path with the terminal on the top of Pikes Peak this scattered component is not noticeable, as

$751 \mathrm{Mc} / \mathrm{s}$ TABLE MESA, $3 \mathrm{~m}$ DISH AT $8.2 \mathrm{~m}$
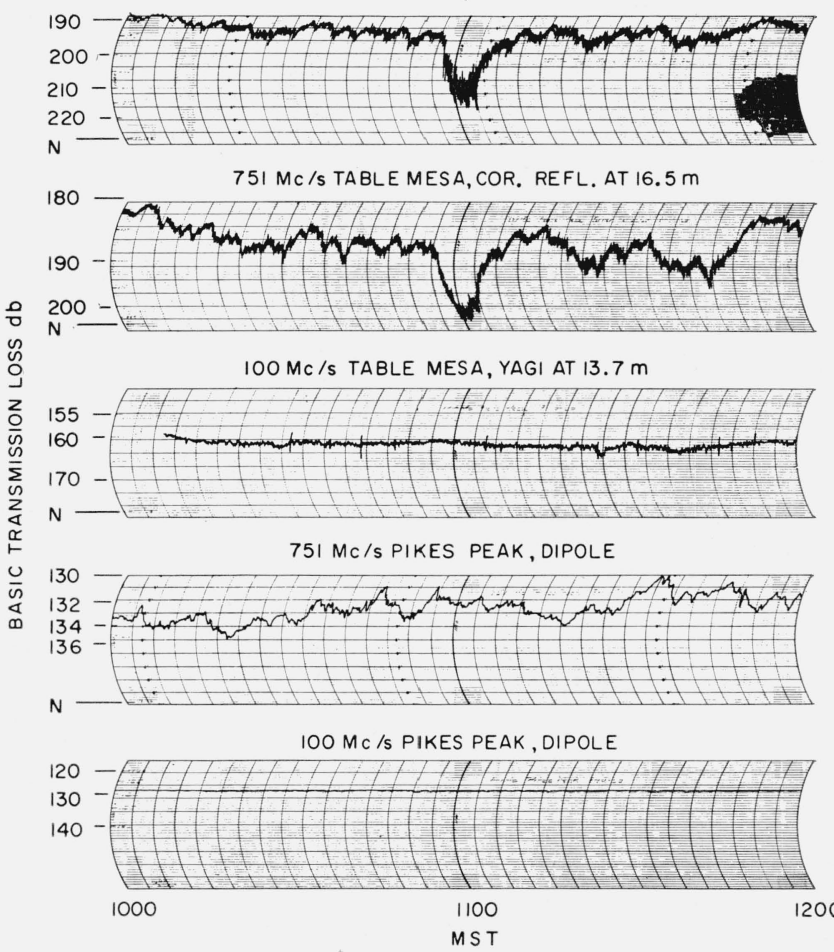

Figure 3. Simultaneous chart recordings for Colorado obstacle gain and line-of-sight propagation paths, August 10, 1960. 
expected. However, the slower variations are still present on $751 \mathrm{Mc} / \mathrm{s}$, and they do not appear correlated with the slow fading observed at the Table Mesa site.

The slow signal variations which are similar to the "space-wave fadeouts" commonly observed on line-of-sight paths will be discussed in more detail later on.

\subsection{Variations of Hourly Medians}

A typical sample of diurnal variations of hourly medians is shown on figure 4 for the period August 8 to 12,1960 , at the Table Mesa receiving site. Each open circle denotes an hourly median of basic transmission loss for the hour given by the abscissa. The distribution of the points and the median curve shows no pronounced diurnal trend. This is in contrast to (smooth earth) diffraction or scatter paths of similar length where usually a substantial diurnal trend of hourly median values is observed.

Similarly, the absence of a pronounced seasonal trend is shown by figure 5. Here, the median of all hourly medians recorded during each 5-day period is plotted versus time. The maximum variation is about $5 \mathrm{db}$. The overall medians obtained for the two antennas appear well correlated, and there seems
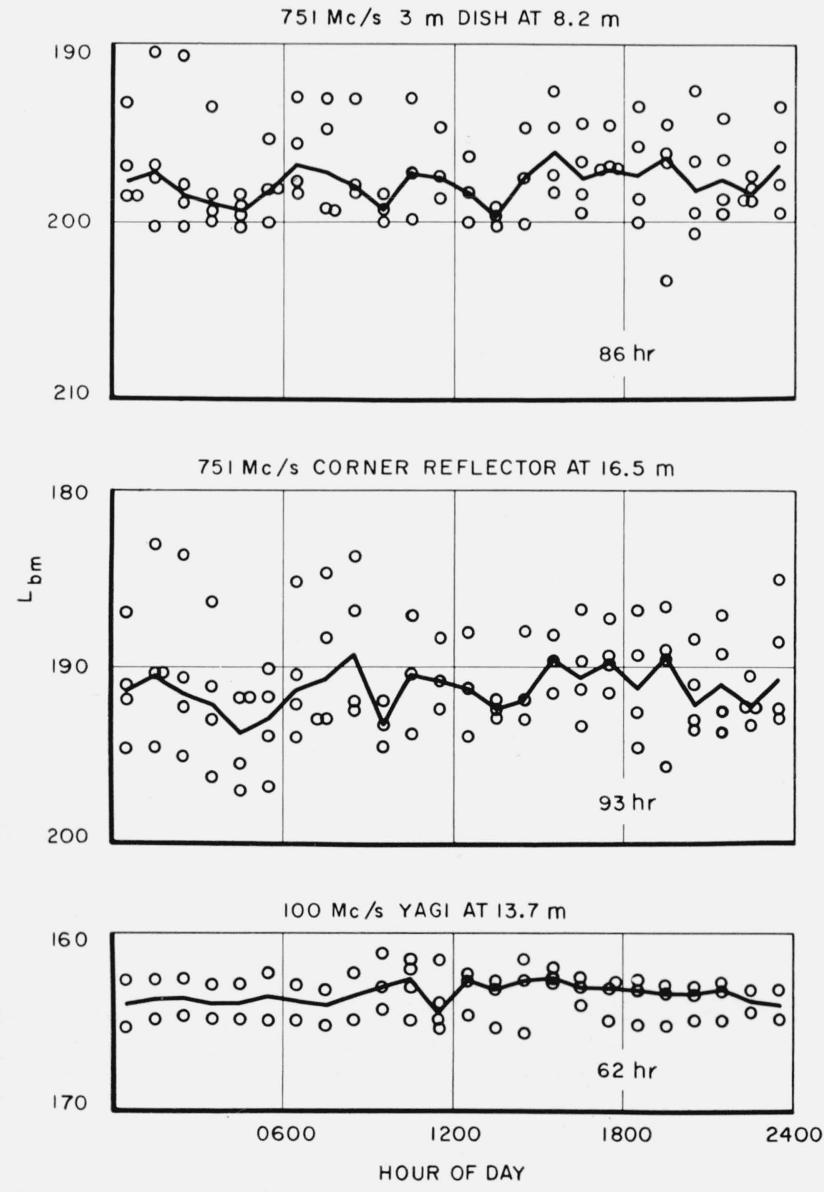

FIgURE 4. Diurnal variations of hourly median transmission loss levels for A ugust 8-12, 1960.

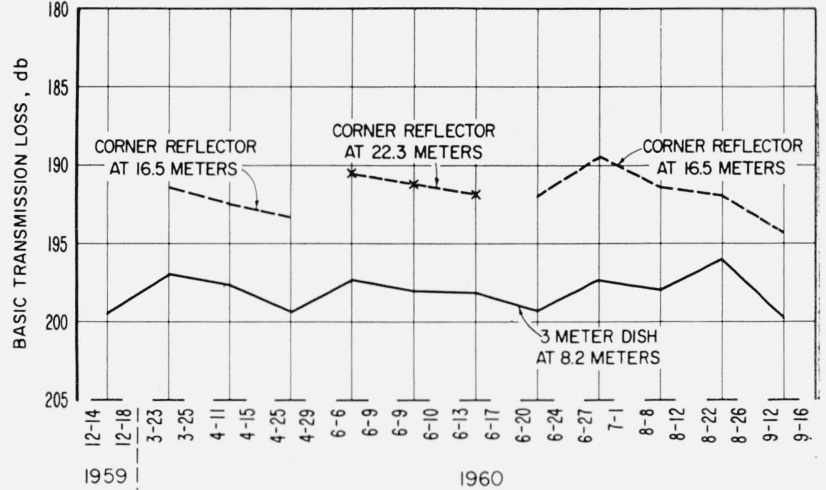

Figure 5. Seasonal trend of overall weekly medians, $751 \mathrm{Mc} / \mathrm{s}$.

to be no significant difference between the results obtained at the two heights used for the corner reflector antenna. During the three recording periods in June when the corner reflector antenna was at the $22.3 \mathrm{~m}$ elevation, the overall medians follow the trend given by the rest of the data, when the $16.5 \mathrm{~m}$ height was used.

The $100 \mathrm{Mc} / \mathrm{s}$ data at Table Mesa and the Pikes Peak data were not included in this study, because they are only available for August and Septembernot enough to study seasonal trends.

It should be recognized that the time periods on figure 5 are consecutive as far as recorded data are concerned. Weeks with no recordings have been omitted.

Diurnal and seasonal variations may also be studied by obtaining distributions of hourly medians for eight time blocks as previously defined [Norton, Rice, and Vogler, 1955]. For this purpose, the hours of the day are divided into four blocks for summer as well as winter months, as follows:

TABLE 2. Time blocks

\begin{tabular}{|c|c|c|}
\hline No. & Months & Hours \\
\hline $\begin{array}{l}1 \\
2 \\
3 \\
4 \\
5 \\
6 \\
\\
8\end{array}$ & $\begin{array}{l}\text { November to April } \\
\text { November to April } \\
\text { November to April } \\
\text { May to October } \\
\text { May to October } \\
\text { May to October } \\
\text { May to October } \\
\text { November to April }\end{array}$ & $\begin{array}{l}0600 \text { to } 1300 \\
1300 \text { to } 1800 \\
1800 \text { to } 2400 \\
0600 \text { to } 1300 \\
1300 \text { to } 1800 \\
1800 \text { to } 2400 \\
0000 \text { to } 0600 \\
0000 \text { to } 0600\end{array}$ \\
\hline
\end{tabular}

Cumulative distributions of the hourly basic transmission loss medians are calculated for each individual time block, or for combinations of time blocks, and plotted on log-normal graph paper. Thus it is possible to obtain an estimate of the range of observed hourly medians which is the long-term fading range. This will be compared with theoretical estimates, or with similar data obtained from other paths.

The cumulative distributions of all measured hourly median transmission loss values are shown on figure 6 separately for all time blocks, and for both $751 \mathrm{Mc} / \mathrm{s}$ antennas, with the corner reflector at the $16.5 \mathrm{~m}$ elevation. All curves are bunched 


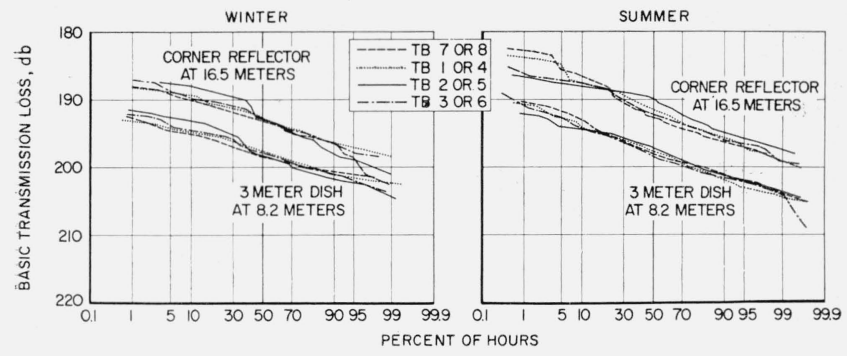

FIgURE 6. Distributions of hourly median basic transmission loss values for Colorado obstacle gain path on $751 \mathrm{Mc} / \mathrm{s}$.

and nearly parallel, indicating very little diurnal or seasonal variation. Table 3 , below, shows a comparison of the overall median values and the longterm fading range. Here the overall median is the median of all hourly medians within a time block, and the long-term fading range is defined as the difference between hourly median values exceeded 1 percent and 99 percent of all hours.

Even though the cumulative distributions of hourly medians plotted by time blocks on figure 6 appear quite similar, table 3 indicates some seasonal effect in the long-term fading range. The range is larger during summer, and is also larger for the corner reflector at the higher elevation than for the dish. There is very little variation in the overall median values between time blocks, and the difference between the dish and the corner reflector appears to be slightly higher in summer.

TABLE 3. Comparison of winter and summer results

\begin{tabular}{|c|c|c|c|c|c|}
\hline \multirow{2}{*}{ Time block No. } & \multicolumn{2}{|c|}{$\begin{array}{l}\text { Overall median } \\
\text { decibels }\end{array}$} & \multirow{2}{*}{$\begin{array}{l}\text { Difference } \\
\text { of overall } \\
\text { medians } \\
\text { db }\end{array}$} & \multicolumn{2}{|c|}{$\begin{array}{l}\text { Long-term fading } \\
\text { range, decibels } \\
\text { (1\% to } 99 \%)\end{array}$} \\
\hline & $3 \mathrm{~m}$ dish & $\begin{array}{l}\text { Corner } \\
\text { reflector }\end{array}$ & & $3 \mathrm{~m}$ dish & $\begin{array}{l}\text { Corner } \\
\text { reflector }\end{array}$ \\
\hline \multicolumn{6}{|l|}{$\begin{array}{l}\text { Winter: } \\
8(0000 \text { to } 0600)\end{array}$} \\
\hline $\begin{array}{l}8(0000 \text { to } 0600) \\
1(0600 \text { to } 1300)\end{array}$ & 198. 4 & 193. 2 & 5. 2 & 8. 9 & 14. \\
\hline $2(1$ & 198 & 192 & $\begin{array}{l}5.0 \\
5.5\end{array}$ & $\begin{array}{r}8.9 \\
12.4\end{array}$ & 10. \\
\hline 3 (1800 to 24 & 197.9 & 192.7 & 5.2 & 11.5 & \\
\hline \multicolumn{6}{|l|}{ Summer: } \\
\hline $7(0000$ to 0600$)$ & 198.1 & 192 & 5.4 & 13.5 & \\
\hline $4(0$ & 197 & 191 & 6.2 & 13.8 & \\
\hline & 197. & 189 & 7.4 & 11.4 & \\
\hline $6(1800$ to 2400$)$ & 198. 5 & 192.3 & 6.2 & 13.0 & 12.9 \\
\hline
\end{tabular}

\subsection{Comparative Studies of Median Distributiors}

Although tropospheric scatter is not primarily involved in these experiments, it is of interest to compare first the measured distributions with theoretically expected values and with data from tropospheric scatter paths baving similar path parameters. For this purpose, two hypothetical paths and the measured results obtained from two actual tropospheric scatter paths were used. The two hypothetical paths were considered to have the same antenna height as the actual path. One was assumed to have an angular distance which a tropospheric scatter path of the same length would have over a smooth earth, and the other would have a path length corresponding to a smooth earth path having the same angular distance as the obstacle gain path. The actually measured paths were selected to correspond closely to these assumptions in path geometry and frequency. Table 4, below, shows the path constants used:

TABLE 4. Path constants for comparative study

\begin{tabular}{|c|c|c|}
\hline & $\begin{array}{c}\text { Path } \\
\text { distance }\end{array}$ & $\begin{array}{l}\text { Angular } \\
\text { distance }\end{array}$ \\
\hline & $\mathrm{km}$ & Milliradians \\
\hline $\begin{array}{l}\text { Hypothetical path A } \\
\text { Hypothetical path B. }\end{array}$ & $\begin{array}{l}223 \\
566\end{array}$ & $\begin{array}{l}24.0 \\
64.4\end{array}$ \\
\hline $\begin{array}{l}\text { Actual paths: } \\
\text { Pikes Peak obstacle gain }(751 \mathrm{Mc} / \mathrm{s}) \\
\text { Cheyenne Mt. to Garden City }(1046 \mathrm{Mc} / \mathrm{s}) \\
\text { Cheyenne Mt. to Anthony }(1046 \mathrm{Mc} / \mathrm{s})\end{array}$ & $\begin{array}{l}223 \\
364 \\
633\end{array}$ & $\begin{array}{l}64.4 \\
26.7 \\
59.8\end{array}$ \\
\hline
\end{tabular}

Overall time block medians and the long-term fading ranges for the hypothetical paths were determined from a consideration of the expected longterm variation of hourly medians. These distributions are obtained from the empirical $V(p, \theta)$ curves, which were determined from a large amount of experimental data representing a number of different geographical and climatic regions within the United States [Rice, Longley, and Norton, 1959]. The time block medians and long-term fading ranges given there are measured relative to a calculated reference value of basic transmission loss, which is the median of all hourly median values in time block 2 (winter afternoon). The curves are assumed to be valid for all frequencies in the 70 to $4000 \mathrm{Mc} / \mathrm{s}$ range.

A comparison of the long-term fading range determined in this manner for the hypothetical paths with the ones measured on the Pikes Peak obstacle gain path is shown as table 5 for all time blocks separately, for all hours during summer and winter, and for all hours of the year.

TABLE 5. Comparison of hypothetical tropospheric propagation paths data with measured data from Pikes Peak obstacle gain path

\begin{tabular}{|c|c|c|c|}
\hline \multirow[b]{2}{*}{ Time block } & \multicolumn{3}{|c|}{ Long term fading range, db ( $1 \%$ to $99 \%)$} \\
\hline & $\begin{array}{l}\text { Hypothetical } \\
\text { path } \mathrm{A}, 223 \\
\mathrm{~km}, \theta=24 \\
\text { milliradians }\end{array}$ & $\begin{array}{l}\text { Hypothetical } \\
\text { path } \mathrm{B}, 566 \\
\mathrm{~km}, \theta=64.4 \\
\text { milliradians }\end{array}$ & $\begin{array}{l}\text { Pikes Peak } \\
\text { obstacle gain } \\
\text { path, } 223 \mathrm{~km} \text {, } \\
\theta=64.4 \mathrm{millira}- \\
\text { dians ( } 3 \mathrm{~m} \text { dish) }\end{array}$ \\
\hline $\begin{array}{l}8 \text { (winter) } \\
1 \\
2 \\
3\end{array}$ & $\begin{array}{l}42.1 \\
37.6 \\
32.9 \\
39.2\end{array}$ & $\begin{array}{l}21.1 \\
13.9 \\
14.0 \\
16.3\end{array}$ & $\begin{array}{r}8.9 \\
8.9 \\
12.4 \\
11.5\end{array}$ \\
\hline $\begin{array}{l}7 \text { (summer) } \\
4 \\
5 \\
6\end{array}$ & $\begin{array}{l}42.2 \\
37.7 \\
25.1 \\
36.5\end{array}$ & $\begin{array}{l}21.4 \\
28.1 \\
18.2 \\
19.0\end{array}$ & $\begin{array}{l}13.5 \\
13.8 \\
11.4 \\
13.0\end{array}$ \\
\hline $\begin{array}{l}\text { All hours, winter. } \\
\text { All hours, summer } \\
\text { All year. }\end{array}$ & $\begin{array}{l}38.8 \\
41.9 \\
39.7\end{array}$ & $\begin{array}{l}19.3 \\
26.0 \\
26.4\end{array}$ & $\begin{array}{l}11.7 \\
13.4 \\
14.3\end{array}$ \\
\hline
\end{tabular}

It is seen that the actually observed long-term fading ranges were considerably smaller than the ones predicted on the basis of scatter propagation, although the fading predicted for a scatter path 
having the same angular distance is a somewhat better estimate.

In order to provide a more valid basis for estimating long-term fading ranges and the distribution of hourly medians for knife-edge diffraction paths, use is made of a method suggested by K. A. Norton. The results of this method as applied to the Pikes Peak obstacle gain path will be compared with the actual measurements in what follows.

For the purpose of studying variations in hourly median field strength or transmission loss values a knife-edge diffraction path is considered to consist of two line-of-sight paths in tandem. The diffracting knife-edge constitutes a common terminal for the two paths. If the hourly median signal for each of the two line-of-sight paths is subject to random variations, $V_{1}$ and $V_{2}$, then the random variation $V$ expected on the mountain obstacle path would be $V=V_{1}+V_{2}$, where $V, V_{1}$, and $V_{2}$,

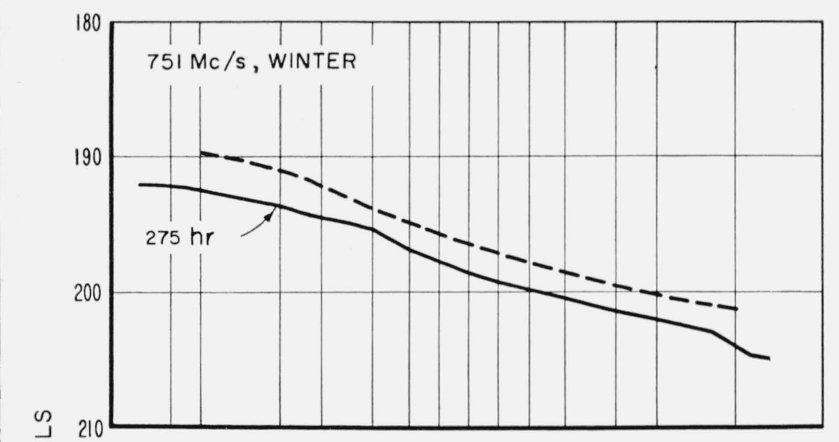

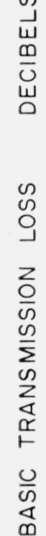
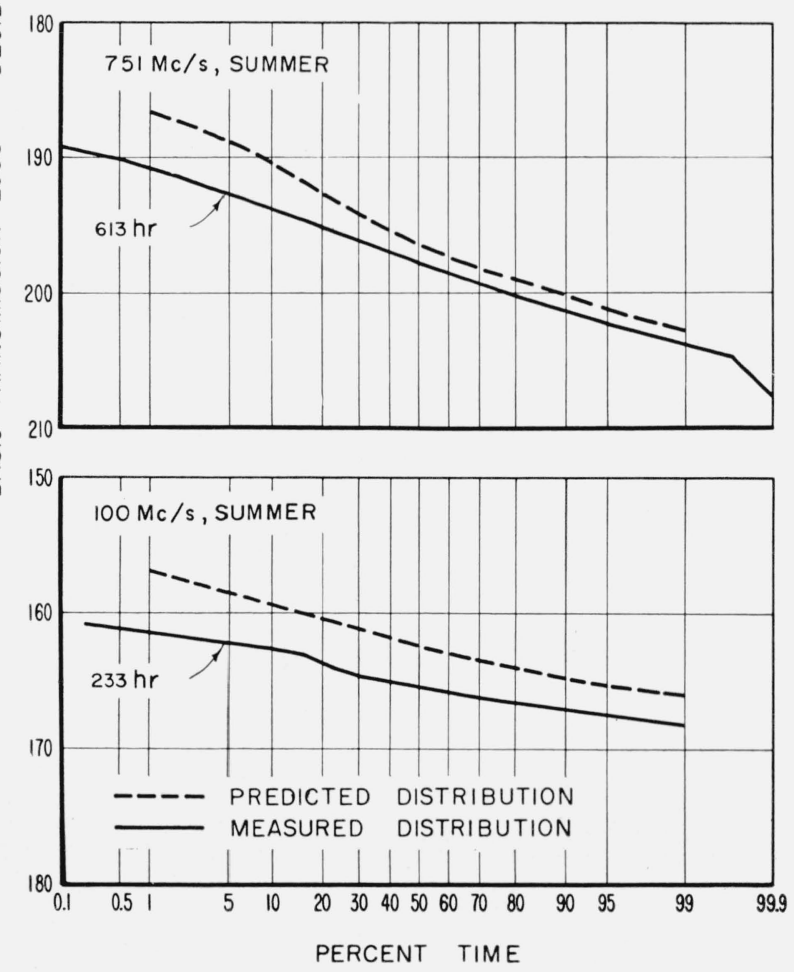

FIGURE 7. Predicted and measured cumulative distributions of basic transmission loss hourly medians, December 1959 to September 1960. are random variables expressed in decibels. The resulting cumulative distribution of hourly medians for the entire path may be determined by the convolution of the distributions of $V_{1}$ and $V_{2}$ [Davenport and Root, 1958].

The cumulative distributions of hourly medians for the two individual line-of-sight paths may be calculated by empirical formulas as functions of the path distance, the effective antenna heights, the carrier frequency, the horizon elevation angles, and season, summer or winter. The methods used are unpublished empirical methods communicated to the authors by P. L. Rice. This material will be described in detail in forthcoming NBS Technical Notes and in a U.S. Air Force Technical Order dealing with design procedures for tropospheric communication circuits. Results are shown on figure 7 , where the empirical distributions are compared with the actually measured distributions. Comparison is made for the data on $751 \mathrm{Mc} / \mathrm{s}$ obtained using the 3-m dish separately for all hours during the summer and during the winter months, and for the $100 \mathrm{Mc} / \mathrm{s}$ data for the summer months.

Calculation of the empirical distributions of hourly medians shown on figure 7 includes determination of the overall median reference value by Fresnel diffraction and ray opties methods which will be discussed in more detail in section 3 below. What is primarily important here is the comparison of the slopes of the actually measured and the empirically predicted distribution curve shown on figure 7 , rather than their absolute position on the basic transmission loss scale.

The comparison of measured and predicted fading. ranges from figure 7 is summarized in table 6 below.

TABLE 6. Comparison of actually measured fading ranges with empirical predictions for Pikes Peak obstacle gain path

\begin{tabular}{|c|c|c|}
\hline & \multicolumn{2}{|c|}{$\begin{array}{l}\text { Long-term fading range, } \\
\text { in decibels }(1 \% \text { to } 99 \%)\end{array}$} \\
\hline & $\begin{array}{l}\text { Actually } \\
\text { measured }\end{array}$ & $\begin{array}{l}\text { Empirical } \\
\text { prediction }\end{array}$ \\
\hline $\begin{array}{l}7_{51} \mathrm{Mc} / \mathrm{s} \text { : } \\
\text { All hours, winter } \\
\text { All hours, summer }\end{array}$ & $\begin{array}{l}11.7 \\
13.4\end{array}$ & $\begin{array}{l}11.5 \\
16.2\end{array}$ \\
\hline $\begin{array}{l}100 \mathrm{Mc} / \mathrm{s} \text { : } \\
\text { All hours, summer }\end{array}$ & 7.0 & 9. 0 \\
\hline
\end{tabular}

Table 6 shows that the empirical method just described provides much better estimates of the long-term fading range than the assumption of a tropospheric scatter path of the same linear or angular distance. This conclusion applies to this specific knife-edge diffraction path, and should be tested against data obtained from other knifeedge paths in order to arrive at an estimate of the uncertainty inherent in the prediction process. However, agreement of the predicted 1 to 99 percent long-term fading ranges is well within the sampling error of the empirical data on which this prediction is based and this suggests that the proposed method of predicting long-term fading ranges is a reliable one. 


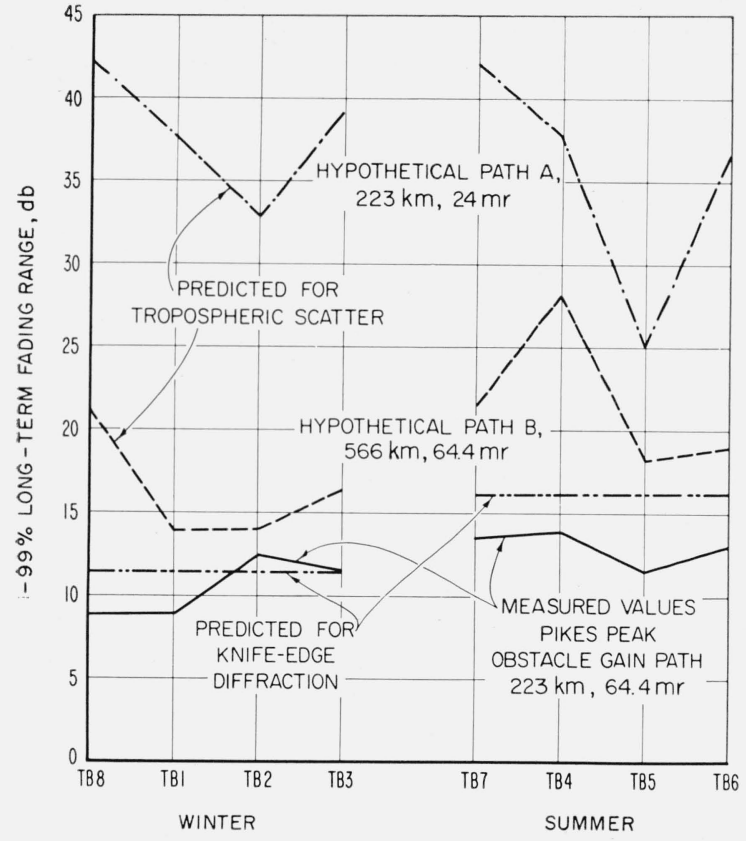

Figure 8. Comparison of predicted and measured diurnal and seasonal variations of the long-term fading range.

The data in tables 5 and 6 have been plotted on figure 8 to obtain a better picture of the comparison between predicted and measured long-term fading ranges and their diurnal trends. As the empirical prediction method just mentioned does not distinguish between individual time blocks, it is represented by a straight line for all summer and winter time blocks, respectively. In spite of the large discrepancy between the measured fading ranges and the ones predicted on the basis of scatter propagation, it is of interest to note that the predicted diurnal trend is evident in the measured data for the summer time blocks, although to a considerably lesser degree. This is not the case for the winter time blocks due to the relatively large measured Time Block 2 long-term fading range.

An additional comparison of the measurement results was made with similar data obtained from two actually measured tropospheric propagation paths which represent a geographical location similar to the Pikes Peak obstacle gain path. In addition thereto, these paths correspond most closely to the hypothetical paths described above in path distance and angular distance, and at the same time, represent a similar carrier frequency. The hourly median distributions for these two paths were taken from unpublished reports. A description of the paths and the various experiments conducted have been published by NBS [Barsis, Herbstreit, and Hornberg, 1955].

Figure 9 compares the distribution of hourly medians measured during the summer months over the Pikes Peak obstacle gain path, with the two paths between Cheyenne Mountain and points in the eastern plains. It is seen that the long-term fading range is smallest for the obstacle gain path;

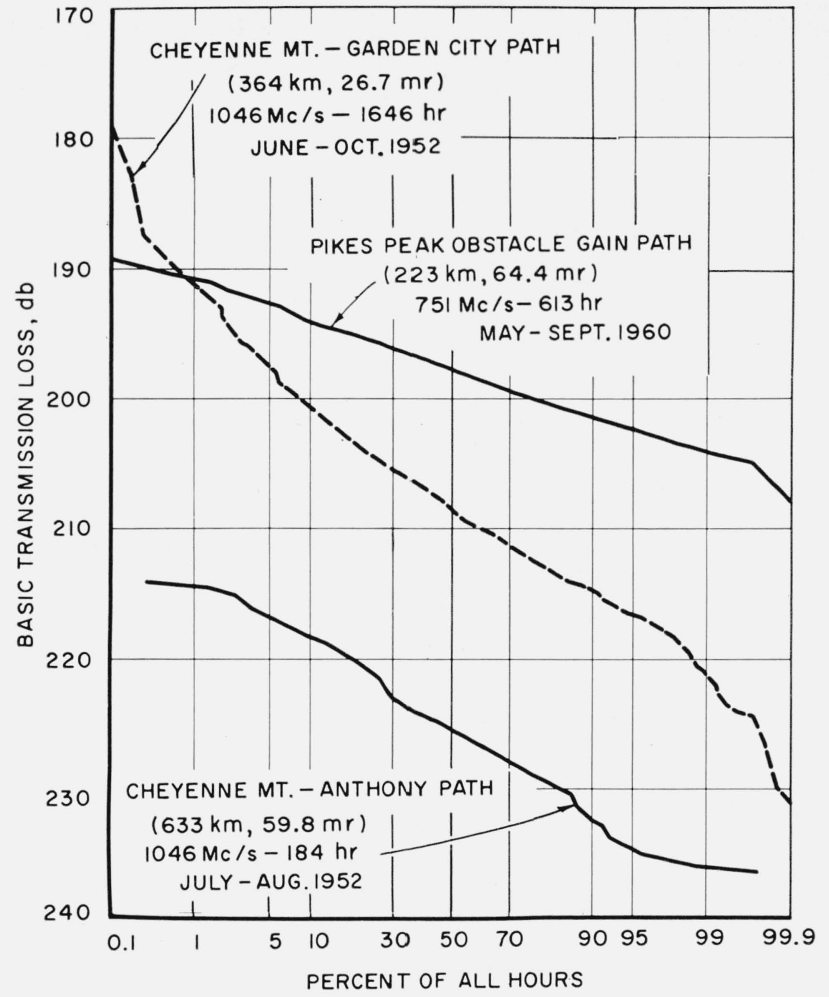

Figure 9. Cumulative distributions of hourly median basic transmission loss values for Colorado-Kansas propagation paths.

it is quite large for the Garden City path which represents the same linear patb distance, and slightly larger for the Anthony path which represents the same angular distance, but a substantially greater linear path distance. Table 7 shows the comparison of overall median values and ranges taken from figure 9 .

TABLE 7. Comparison of long tropospheric propagation path results

\begin{tabular}{c|r|r|r|r|r}
\hline \hline Path & $\begin{array}{c}\text { Fre- } \\
\text { quency } \\
\text { Mc/s }\end{array}$ & Time period & $\begin{array}{c}\text { No. of } \\
\text { hours }\end{array}$ & $\begin{array}{c}\text { Basic } \\
\text { transm. } \\
\text { loss } \\
\text { overall } \\
\text { median } \\
\text { db }\end{array}$ & $\begin{array}{c}\text { Long-term } \\
\text { fading } \\
\text { range, db } \\
(1 \% \text { to 99\% })\end{array}$ \\
\hline $\begin{array}{c}\text { Pikes Peak } \\
\text { obstacle gain. }\end{array}$ & 751 & Summer 1960--- & 613 & 198.7 & 13.4 \\
$\begin{array}{c}\text { Cheyenne Mt. } \\
\text { Garden City. } \\
\text { Cheyenne Mt. } \\
\text { Anthony. }\end{array}$ & 1046 & Summer 1952--- & 1646 & 208.9 & 30.5 \\
\hline
\end{tabular}

The overall medians have been added for completeness of the information. It is quite clear that transmission loss tends to be smaller for a knife-edge diffraction path as compared to tropospheric scatter paths of similar length. Perhaps even more significant is the substantial reduction in the long-term fading range. Although there are fewer hours of measurements available for the Cheyenne MountainAnthony path, table 6 shows that a tropospheric scatter path of comparable linear distance has a 
substantially greater long-term fading range than an obstacle gain path, whereas a scatter path of similar angular distance has only a moderately greater long-term fading range. This agrees well with the results obtained by the application of empirical methods for determining fading rangethe method based on scatter propagation paths yielding substantially greater fading ranges than the method based on line-of-sight paths.

\subsection{Frequency Dependence of the Distributions of Hourly Medians}

Figure 10 shows a comparison of all measured data on $100 \mathrm{Mc} / \mathrm{s}$ and $751 \mathrm{Mc} / \mathrm{s}$ during the two weekly periods when the receiver site on Pikes Peak was operated. These are overall summer-time distributions; they have not been separated into time blocks because of the comparatively few hours available. As expected, the long-term fading range is smaller for the line-of-sight path to the top of the

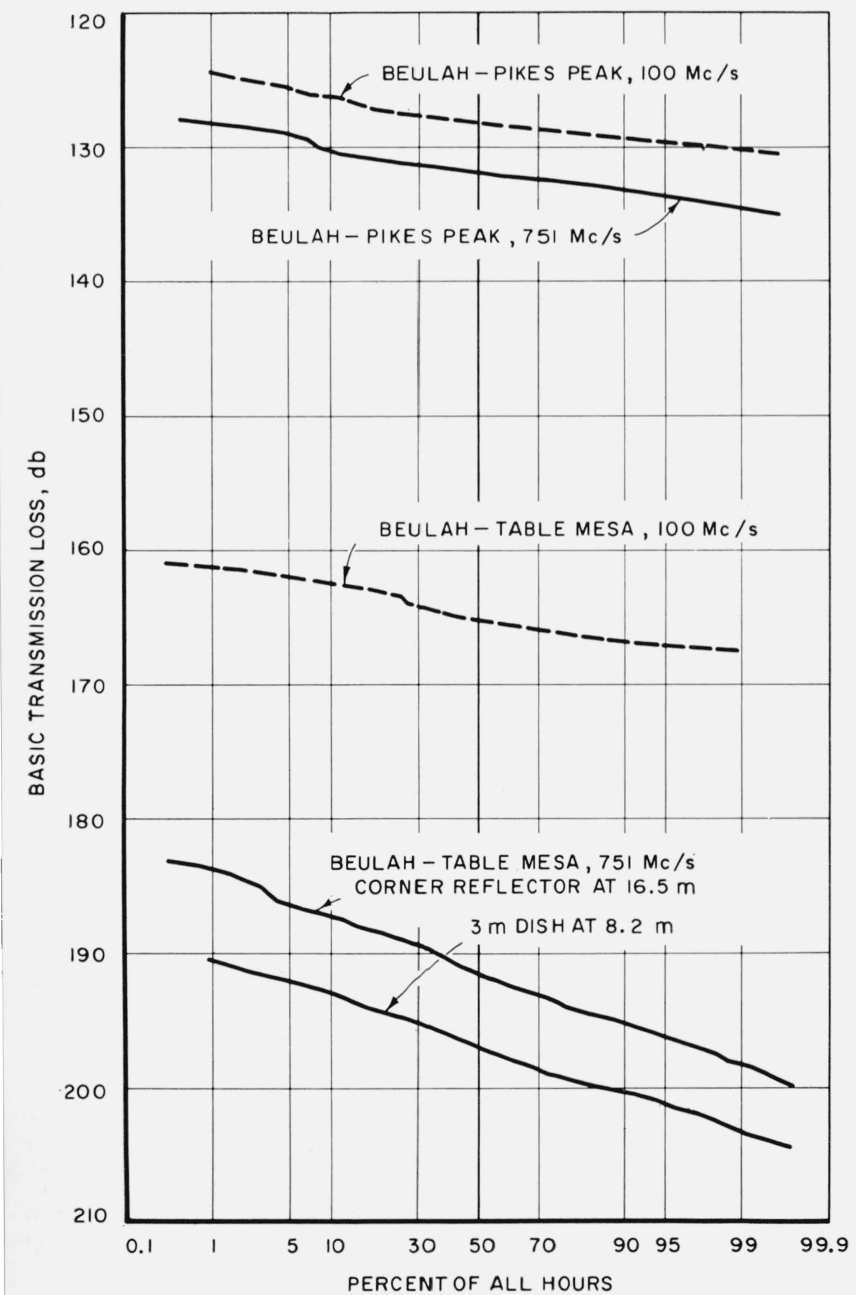

Figure 10. Measured distributions of hourly median basic transmission loss values for August 8-12 and 22-26, 1960. peak than for the obstacle gain path. Overall median and ranges for this period are given in table 8 below.

TABLE 8. Data from distributions of hourly medians

\begin{tabular}{|c|c|c|}
\hline Path and frequency & $\begin{array}{l}\text { Basic } \\
\text { transmission } \\
\text { loss overall } \\
\text { Median, db }\end{array}$ & $\begin{array}{l}\text { Long-term } \\
\text { fading range, db } \\
(1 \% \text { to } 99 \%)\end{array}$ \\
\hline $\begin{array}{l}\text { Beulah-Pikes Peak, } 100 \mathrm{Mc} / \mathrm{s} \\
\text { Beulah-Pikes Peak, } 751 \mathrm{Mc} / \mathrm{s}- \\
\text { Beulah-Table Mesa, } 100 \mathrm{Mc} / \mathrm{s} \\
\text { Beulah-Table Mesa, } 751 \mathrm{Mc} / \mathrm{s} \text { (dish) } \\
\text { Beulah-Table Mesa, } 751 \mathrm{Mc} / \mathrm{s} \text { (corner) }\end{array}$ & $\begin{array}{l}128.2 \\
132.0 \\
165.3 \\
197.0 \\
191.6\end{array}$ & $\begin{array}{r}5.7 \\
6.3 \\
7.0 \\
13.0 \\
14.7\end{array}$ \\
\hline
\end{tabular}

This tabulation shows a substantial frequency dependence of the fading range for the obstacle gain path - more than doubled when comparing $100 \mathrm{Mc} / \mathrm{s}$ with either one of the $751 \mathrm{Mc} / \mathrm{s}$ antennas. There is not nearly that much frequency dependence on the line-of-sight path. It has already been shown that the $V(p, \theta)$ distributions are not appropriate for use in predicting the performance of knife-edge diffraction paths, and that much better agreement is obtained by the use of a different empirical method taking into account carrier frequency and horizon elevation angles.

\section{Height Gain Studies}

Previous measurements made of obstacle diffraction over Pikes Peak [Kirby, Dougherty, and McQuate, 1955] showed marked agreement between the predicted and observed variation of transmission loss with height. These measurements were made using a shorter path and with a relatively smooth terrain area in the immediate foreground of the antenna whose height was varied.

The $751 \mathrm{Mc} / \mathrm{s}$ equipment installed on Table Mesa permitted the collection of similar data for antenna heights up to $100 \mathrm{ft}$ using a telescopic tower with dual receivers and recorders. However, the Table Mesa site differs from the receiving site previously used in that the terrain is very rough except for a small flat area immediately in front of the receiver site, which is only large enough for approximately one-third of the first Fresnel-zone ellipse. It has been previously shown that the cumulative distributions of hourly basic transmission loss medians for the two antenna heights on $751 \mathrm{Mc} / \mathrm{s}$ have approximately the same dispersion and the medians are separated by approximately $5 \mathrm{db}$ in winter, and up to $7.4 \mathrm{db}$ in summer. Using a small stored-program electronic computer the height distribution of field strength or basic transmission loss was calculated by methods of geometrical optics using the vector sum of four rays [Dickson, Egli, Herbstreit, and Wickizer, 1953; Crysdale, Day, Cook, Psutka, and Robillard, 1957]. Each of the rays has a magnitude and phase value determined by reflections from the ground and diffraction by the knife-edge type obstacle. The reflecting planes were assumed to be parallel to a smooth earth's surface, and to pass through the bases of the antenna towers. Reflection 
coefficients of 0.5 and 0.9 were assumed, with a phase shift of $180^{\circ}$ occurring at the reflecting planes. The attenuation and phase-shift at the obstacle were calculated using the asymptotic expansions for Fresnel integrals [Schelleng, Burrows, and Ferrell, 1933]. This was justified due to the magnitude of the parameters involved. For all calculations a refractivity value $N_{s}=290$ was assumed, which corresponds to average winter afternoon for the geographical region where the measurements were made. Changes in the $N_{s}$ value within the range 240 to $320 N$-units did not materially affect the relative height dependence of basic transmission loss.

A height-gain run was performed in the morning hours of March 25, 1960. For each position of the corner reflector antenna (mounted on the telescopic tower) the basic transmission loss was determined for both receiving antennas, so that the values measured could be corrected for changes recorded on the fixed antennas. The results are plotted versus receiving antenna height on the subsequent figures in order to permit comparison with calculated values using various parameters.

Figure 11 shows the comparison of the measured height dependence with calculated values, using reflection coefficients of 0.9 and 0.5 . There is no agreement in the magnitude of the transmission loss or in the number of lobes. The measured data show only one lobe with a maximum at approximately $21 \mathrm{~m}$ above ground, whereas the theoretical calculations predict 4 to 5 lobes within the height interval measured. A change in the reflection coefficient only changes the magnitude of the maxima and minima. Similarly, any change in the assumed

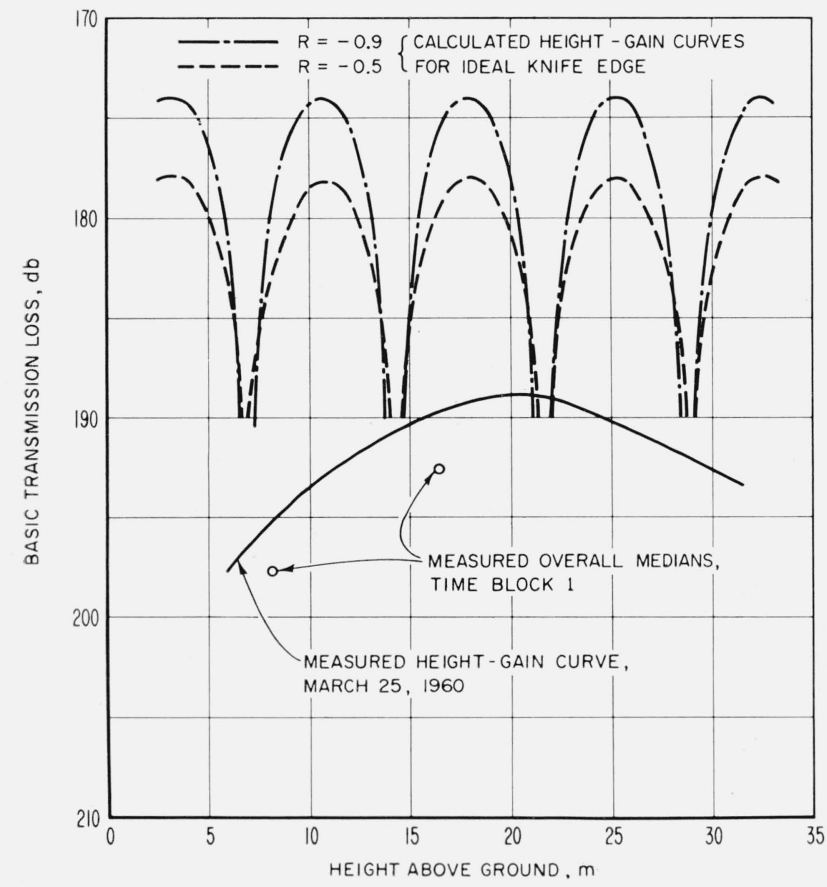

Figure 11. Comparison of calculated and measured height-gain curves for Colorado obstacle gain path. elevation of the transmitting antenna has little or no effect upon the position and number of lobes at the receiver, but can modify the transmission loss. approximately the same amount at all heights. Height-gain experiments using the transmitting antenna were not performed.

Studies were also made assuming the cross section along the profile of the refracting knife-edge to be rounded. The terrain profile cross section through the top of Pikes Peak can be approximated by a circular are with a radius of roughly $11.5 \mathrm{~km}$. Following, in general, the rounded knife-edge procedure [Wait and Conda, 1959], the resultant diffracted field as a function of receiving antenna height was calculated again as the vector sum of four rays, each of which is affected by the rounded obstacle and by reflections from the terrain in the foreground of the antennas. These results are shown on figure 12 , together with the measured height-gain run and the theoretical curve for the ideal knife-edge. Both theoretical curves are based on a reflection coefficient of 0.9 . It is seen that only the absolute values of transmission loss are affected by "rounding." the knife-edge; the number and position of the lobes with antenna height remains the same. Additional calculations show that the change in transmission loss depends on the radius of curvature assumed; as this is somewhat arbitrary for this terrain configuration, the assumption of $11.5 \mathrm{~km}$ depends on how much of the profile the arc is fitted to.

Figure 11 shows that the long-term median values of transmission loss observed on the dish at 8.2 $\mathrm{m}$ and the corner reflector at $16.5 \mathrm{~m}$ have approximately the same difference as is indicated by the

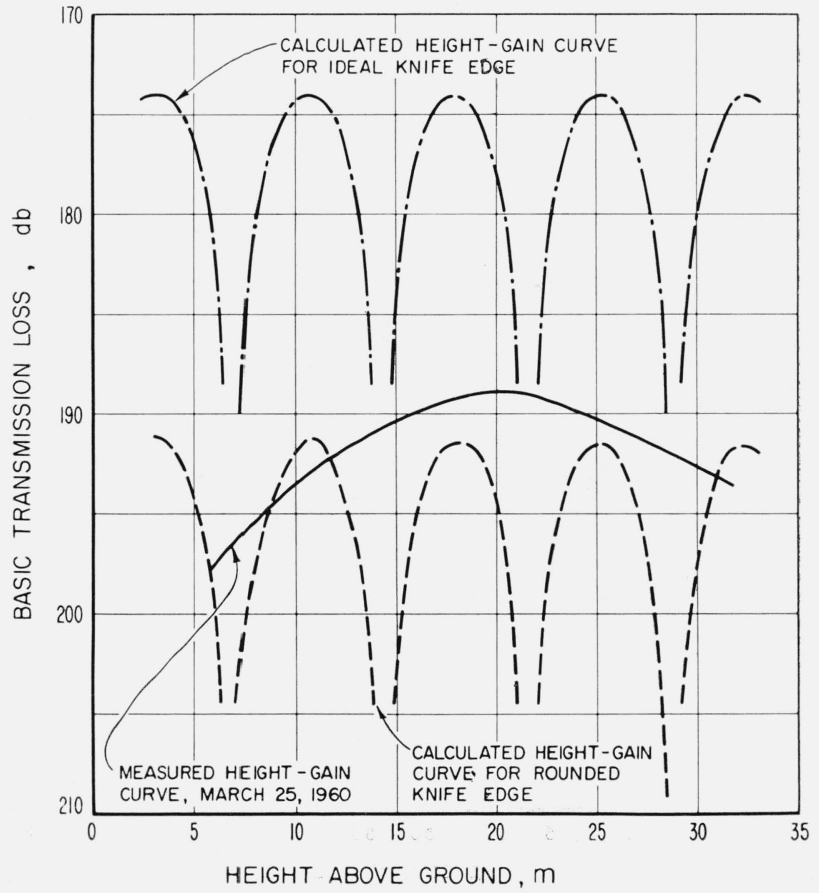

Figure 12. Comparison of calculated and measured height-gain curves for Colorado obstacle gain path. 


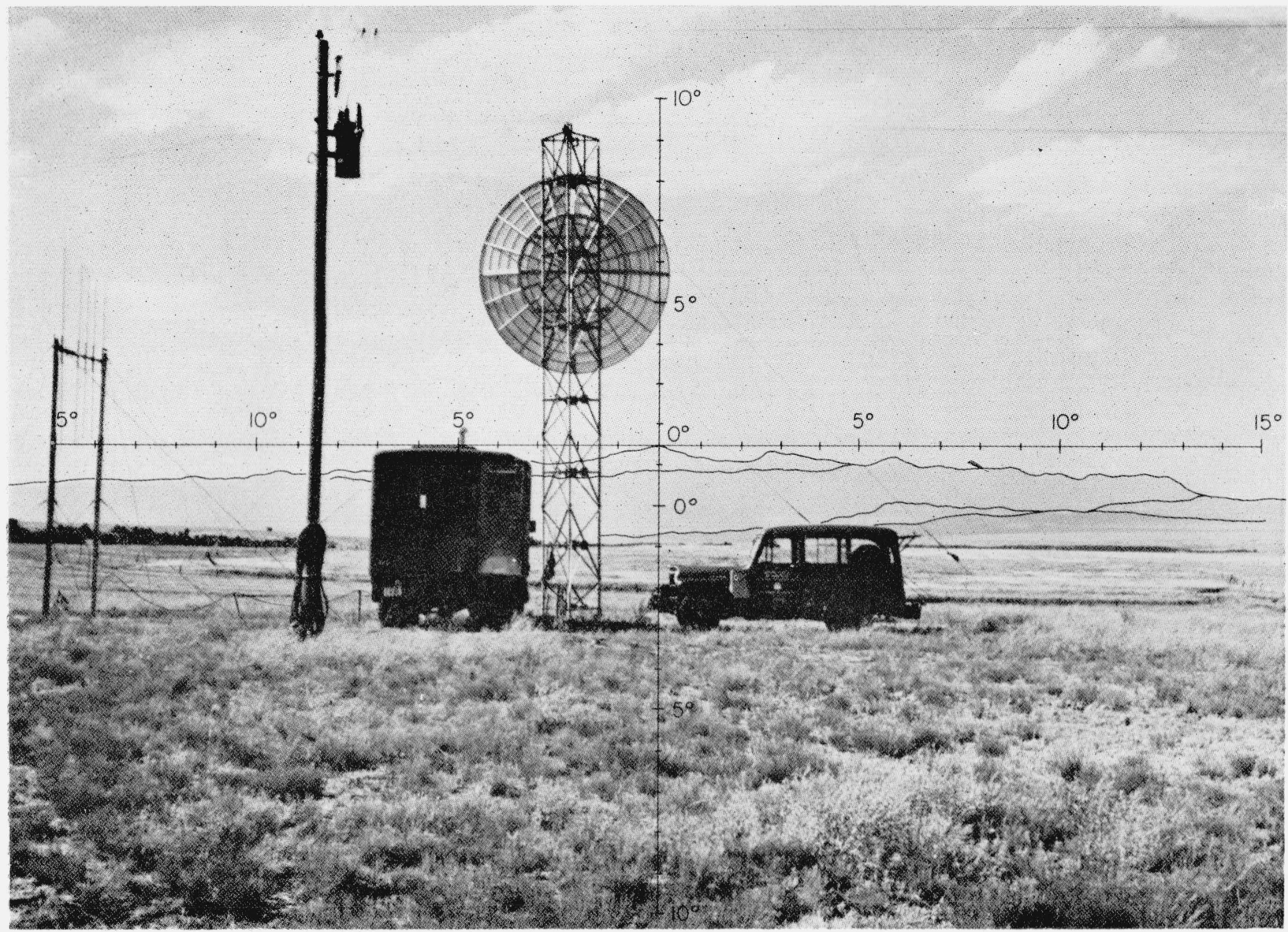

Figure 13. Transverse profile through Pikes Peak as seen from transmitter site.

measured height gain curve. For the two different heights used for the higher antenna (corner reflector at 16.5 and $22.3 \mathrm{~m}$ ) there is little difference in the values of transmission loss observed. This tends to confirm the similarity of long-term transmission loss values observed at the two heights as shown in figure 5.

It is quite clear from the above discussion that the basic transmission loss dependence on antenna height cannot be represented in this case by the simple four-ray knife-edge model, even if the knifeedge is assumed to be rounded. The reason becomes evident if the transverse profile through the obstacle is studied, which is a terrain profile drawn through the obstacle at right angles to the propagation path. Figure 13 is a photograph of the visual horizon as seen from the transmitting antenna with various visible ridge lines emphasized. A grid is superimposed which shows the angles subtended from the transmitting site. It is seen that the transmitting antenna beam, with a $7.7^{\circ}$ half-power beam width sees a substantial portion of the ridge line on either side of the principal obstacle. Similar conditions exist if the transverse profile is viewed from the receiving terminal. Thus field contributions may exist from the ridges and other terrain features between the terminals and Pikes Peak illuminated by the antenna beams. It has so far not been possible to make a quantitative study of these contributions in order to use them for field computations. The effect of a transverse triangular mountain profile was studied by Matsuo in [1950]. Numerical results for a specific example were given but no comparison was made with actual measured results.

\section{Vertical Space Diversity and Fading Characteristics}

A detailed study of the short-term fading characteristics observed on this path is contained in another paper [Barsis and Johnson, 1961]. A number of possible mechanisms appear responsible for the fading. These include those associated with prolonged space-wave fadeouts, which resemble phenomena observed on within-the-horizon paths, as well as those associated with scattering components. Other mechanisms appear to be due to the terrain configuration and may be the cause of an intermediate type of fading, characterized by fadeouts on the order of $5 \mathrm{db}$ which last less than a few minutes.

In view of the apparent positive correlation between the $751 \mathrm{Mc} / \mathrm{s}$ signals recorded simulta- 
neously on the two receiving antennas, studies were performed to determine the correlation coefficient between instantaneous envelope values for various sample periods. For this purpose, the transmission loss information recorded on magnetic tape was digitized and fed into a computer program. The tape contained adequate timing signals to insure proper evaluation without time lag. Table 9, below, contains the time and duration of each sample, the separation of the receiving antennas, and the resulting correlation coefficient. For purpose of digitizing, the magnetic tape was sampled once per second. The correlation coefficients listed apply to basic transmission loss in decibels; a check revealed that results were not materially different if receiver input voltages (proportional to field strength) were correlated.

TABLE 9. Results of envelope correlation studies for Pikes Peak obstacle gain path

\begin{tabular}{|c|c|c|c|}
\hline Date and time of sample (1960) & Length & $\begin{array}{l}\text { Antenna } \\
\text { spacing }\end{array}$ & $\begin{array}{c}\text { Correlation } \\
\text { coefficient }\end{array}$ \\
\hline $\begin{array}{l}\text { June } 13,1745 \text { to } 1800 \\
\text { June } 13,2120 \text { to } 2125 \\
\text { June } 13,2200 \text { to } 2220 \\
\text { June } 14,1010 \text { to } 1020 \\
\text { June } 15,0738 \text { to } 0748 \\
\text { June } 15,1200 \text { to } 1210 \\
\text { June } 15,1800 \text { to } 1805 \\
\text { June } 16,0350 \text { to } 0400 \text { to } 1710 \\
\text { September } 15,17000 \text { to } 1930 \\
\text { September } 15,1920 \text { to } 1930 \text { ber } 15,2126 \text { to } 2146 \\
\text { September } 16,0255 \text { to } 0305 \\
\text { September } 16,1015 \text { to } 1025 \\
\text { September } 16,1120 \text { to } 1130\end{array}$ & $\begin{array}{r}\text { Minutes } \\
15 \\
5 \\
20 \\
20 \\
10 \\
10 \\
5 \\
10 \\
10 \\
10 \\
20 \\
10 \\
10 \\
10\end{array}$ & $\begin{array}{r}\text { Meters } \\
14.1 \\
14.1 \\
14.1 \\
14.1 \\
14.1 \\
14.1 \\
14.1 \\
14.1 \\
8.3 \\
8.3 \\
8.3 \\
8.3 \\
8.3 \\
8.3\end{array}$ & $\begin{array}{l}0.491 \\
.503 \\
.625 \\
.204 \\
.242 \\
.033 \\
.537 \\
.656 \\
.555 \\
.677 \\
.685 \\
.331 \\
.780 \\
.450\end{array}$ \\
\hline
\end{tabular}

The samples were picked to represent different types of the signal as it appeared on the visual recording charts for the two antennas. They are not to be considered taken at random in a statistical sense; therefore they serve only to illustrate the phenomenon, and cannot be used to establish a time or spacing dependence, or similar results. They show, however, that moderately high correlation exists between simultaneous envelope values of the signal received on vertically spaced antennas, and that the correlation coefficient seems to be higher at nighttime and for closer spaced antennas, and that these results make the effectiveness of vertical space diversity questionable for a path of this type. A more complete analysis using many more samples evenly distributed over the recording period would be necessary to draw final conclusions on the diurnal variation and other characteristics of the correlation coefficient.

A visual representation of the instantaneous envelope correlation may be obtained by applying the tape-recorded signals to an $x-y$ plotter. Figure 14 shows two such samples, and a good qualitative idea of the magnitude of the correlation coefficient may be obtained thereby.

Figure 15 shows examples of the correlation coefficient between hourly median values of basic transmission loss. In general, hourly medians tend to be more highly correlated than instantaneous
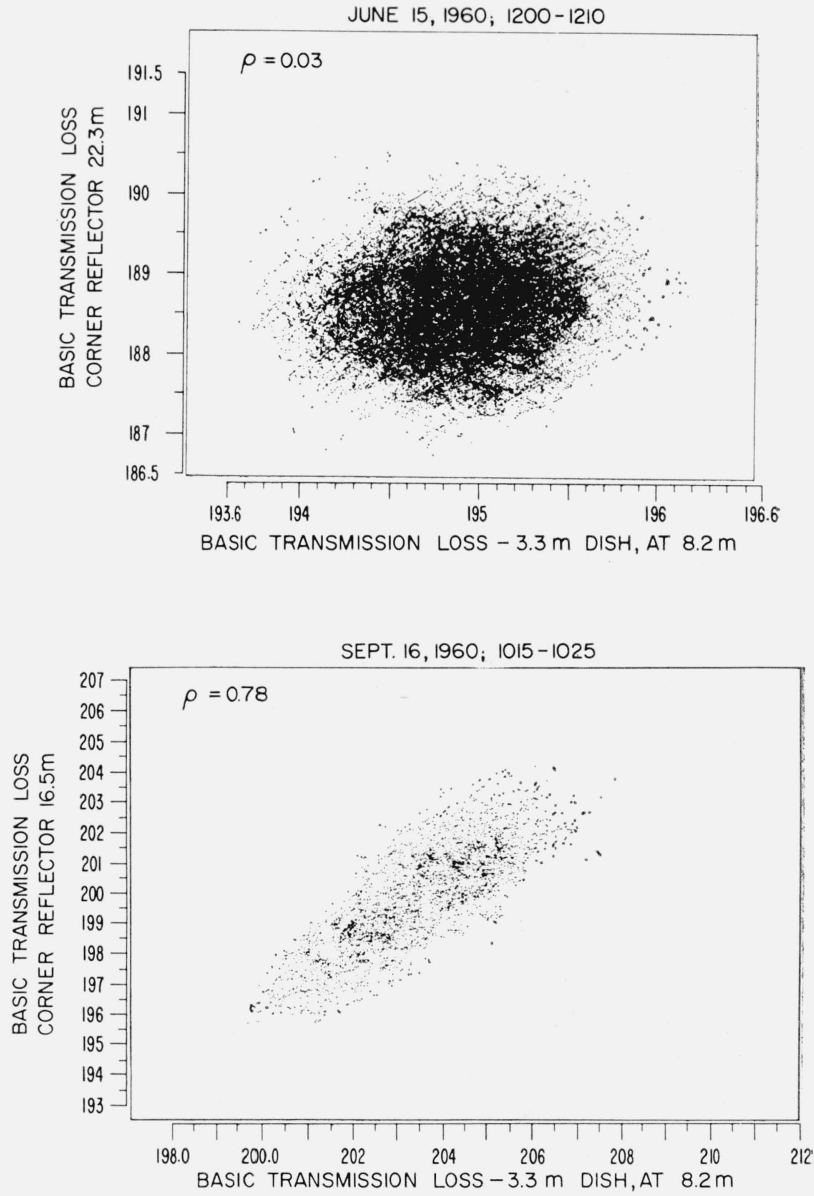

Figure 14. Instantaneous envelope correlation for Colorado obstacle gain path on $751 \mathrm{Mc} / \mathrm{s}$.

values. The two graphs shown represent the two antenna separations used. The correlation coefficient is substantially higher for the closer spaced antennas $(8.3 \mathrm{~m})$. It cannot be determined, however, if this is entirely due to the spacing, as the two samples were taken at different times. The graphs indicate the antenna spacing, the number of hours, the standard deviations of hourly medians for each antenna, and the correlation coefficient. Hourly medians determined with the $3 \mathrm{~m}$ dish are plotted along the $y$-axis, whereas the corner reflector data are plotted along the $x$-axis.

Finally, a new analysis of fade durations and signal distributions is shown on figure 16 . Four periods of record ranging from $6 \mathrm{hr}$ to more than $200 \mathrm{hr}$ each were analyzed to determine the distribution of fades as well as high signal of various levels and duration periods. Each curve shown corresponds to one of these levels, and the points plotted are the percentages of the total time the signal remained either above or below the indicated level for the duration given by the ordinate. The median is the dividing line; for each graph curves to the left of the median represent fades, and the ones to the right represent periods of signal higher than the median. The asymptotic extensions of the curves toward a zero 


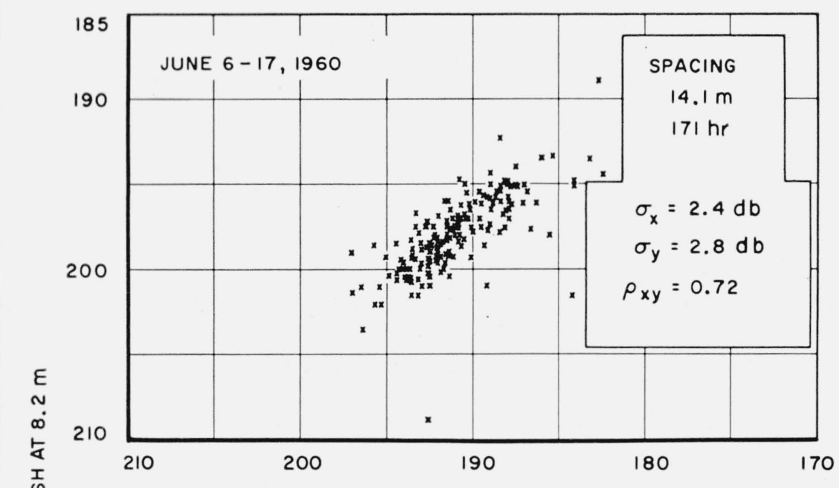

Lbm COR. REFL. AT $22.2 \mathrm{~m}$

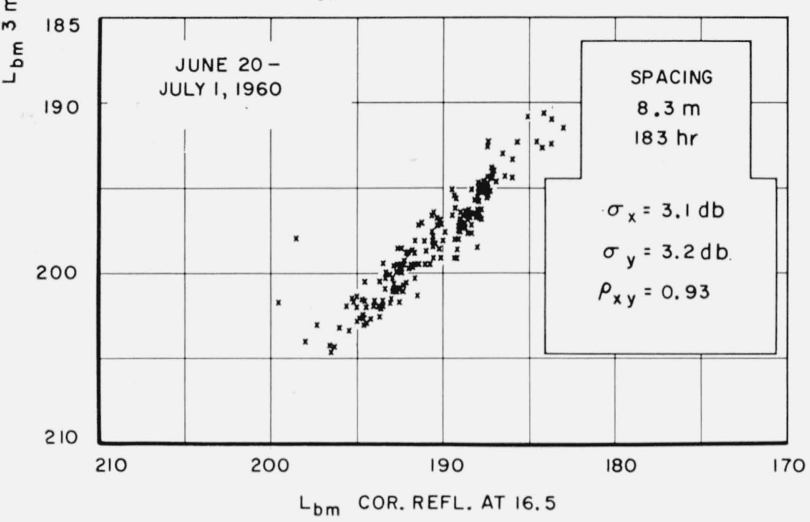

FIGURE 15. Correlation of hourly medians for vertically spaced antennas at $751 \mathrm{Mc} / \mathrm{s}$.

fade or signal duration become the distribution of instantaneous signal levels for each period in the limit. As an example, in the upper right hand graph (period August 8 to 12), the curve labelled " 202 " indicates the distribution of durations when the basic transmission loss exceeded $202 \mathrm{db}: 1$ percent of all "fades" to $202 \mathrm{db}$ was of at least $8 \mathrm{~min}$ duration.

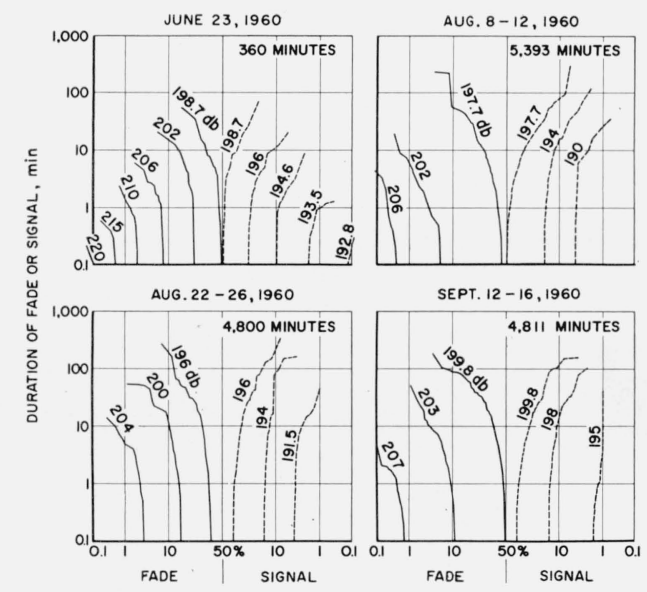

FiguRE 16. $751 \mathrm{Mc} / \mathrm{s}$ fading characteristics observed on 3 meter dish.
This type of representation permits an analysis of fades or short-term variations in terms of basic transmission loss levels, which may be easily related to any arbitrary reference, like the overall median of the period considered. This type of presentation can be used to determine, at least statistically, the characteristics of individual fades. For example it might be of interest to know how many fades occurred whose duration was between 1 and $2 \mathrm{~min}$. The difference between the percentage of the total time the signal fell below the specified level for durations of 1 and 2 min respectively can be read from this type of presentation. From this information the number of fades within this range of duration can easily be determined for the entire period of the analysis.

\section{Conclusions}

The analysis of $751 \mathrm{Mc} / \mathrm{s}$ data from a long obstacle gain path showed principally that the distribution of hourly medians of field strength or basic transmission loss may be approximated by the convolution of cumulative distributions for two line-of-sight paths in tandem which have the obstacle as a common terminal. As expected, these long-term fading characteristics are quite different from the ones observed for tropospheric scatter propagation over comparable distances. No significant diurnal variation in propagation characteristics was observed on the obstaclegain path, and the indication is that seasonal variations are small. Due to the limited width of the obstacle, the knife-edge approximation by a semiinfinite plane, or half-cylinder may not be entirely appropriate, although a somewhat arbitrary assumption of curvature leads to theoretical values of transmission loss equivalent to observed values.

Correlation studies of the signal received on vertically spaced antennas suggest that space diversity may not be very effective on circuits utilizing obstacle gain. Transmission loss recordings show slow and deep fades occurring simultaneously on antennas vertically separated by 14.1 and $8.8 \mathrm{~m}$. Correlation was somewhat lower for the greater spacing.

It is hoped that additional diversity experiments can be performed using this path with the antennas spaced horizontally in line with and normal to the path profile.

The outstanding advantages of obstacle gain paths of this type are that the signal level is significantly higher than expected for scatter paths of comparable length, and the amplitude of rapid Raleigh-fading components is substantially reduced. However, the received field strength is lower than values calculated using the idealized knife-edge theory. This is probably due to the profile through the obstacle, which represents a rounded knife-edge, and to reflections and contributions from other terrain features.

These and similar measurements show that relatively high signal strengths are consistently observed behind mountain ridges. Thus it is unlikely that mountain ranges can always be relied upon to shield 
potential interference. Special consideration to these phenomena should be given in locating radio astronomy or space communication terminals.

The authors thank all the personnel of the Propagation-Terrain Effects Section who contributed to the installation and operation of the equipment, and the collection and the analysis of the data, and Messrs. K. A. Norton and G. W. Haydon for their review and suggestions. Transmission loss calculations for a "rounded" knife-edge were performed by Messrs. H. T. Dougherty and L. J. Maloney. Drafting work was performed by J. C. Harman and his group, and the manuscript was typed by Mrs. D. J. Hunt.

\section{References}

Barsis, A. P., J. W. Herbstreit, and K. O. Hornberg, Cheyenne Mountain tropospheric propagation experiments, NBS Cir. 554 (Jan. 1955).

Barsis, A. P., and M. E. Johnson, Prolonged space-wave fadeouts in tropospheric propagation, NBS Tech. Note No. 88 (Feb. 1961).

Bean, B. R., Prolonged space-wave fadeouts at $1046 \mathrm{Mc} / \mathrm{s}$ observed in Cheyenne Mountain propagation program, Proc. IRE 42, 848-853 (May 1954).

Crysdale, J. M., J. W. B. Day, W. S. Cook, M. E. Psutka, and P. E. Robillard, An experimental investigation of the diffraction of electromagnetic waves by a dominating ridge, IRE Trans. on Antennas and Propagation AP-5, 203-210 (Apr. 1957). See also subsequent discussion by Crysdale in $\mathbf{A P}-\mathbf{6}, 293-295$ (July 1958).

Davenport, W. B. Jr., and W. L. Root, An introduction to the theory of random signals and noise, Chap. 3, 35-37, (McGraw-Hill Book Co., Inc., New York, N.Y., 1958).
Dickson, F. H., J. J. Egli, J. W. Herbstreit, and G. S. Wickizer, Large reductions of VHF transmission loss and fading by the presence of a mountain obstacle in beyondline-of-sight paths, Proc. IRE 41, 967-969 (Aug. 1953). See also subsequent correspondence by Crysdale, and rebuttal by Dickson, et al, in Proc. IRE 43, 627-628 (May 1955).

Hirai, M., Y. Fujii, and H. Saito, An experimental investigation of the diffraction at $\mathrm{VHF}$ and $\mathrm{UHF}$ by mountain ridges, Journal of the Radio Research Lab. (Japan) 5, 189-211 (July 1958).

Kakita, K., F. Iwai, and S. Ieiri, Radio transmission beyondline-of-sight between Kyushu and Anami-Oshima Island, Elec. Commun. Lab. Journal, N.T.T. (Japan) 8, 1183-1213 (1959).

Kirby, R. S., H. T. Dougherty, and P. L. McQuate, Obstacle gain measurements over Pikes Peak at 60 to $1046 \mathrm{Mc} / \mathrm{s}$, Proc. IRE 43, 1467-1472 (Oct. 1955). This paper contains an extensive list of references to previous work.

Kono, T., and M. Hirai, Use of diffraction effect of mountains for $\mathrm{VHF}$ radio communication, Journal of the Radio Research Lab. (Japan) 2, 293-309 (July 1955).

Matsuo, Saburo, The method of calculating V.H.F. field intensity and research on its variation, Report 621.39.001 G(047.3), The Electrical Communication Laboratory, Ministry of Telecommunications, Tokyo, Japan (Aug. 1950).

Nishikori, K., Y. Kurihara, M. Fukushima, and M. Ikeda, Broad and narrow beam investigations of SHF difiraction by mountain ridges, Journal of the Radio Research Lab. (Japan) 4, 407-422 (Oct. 1957).

Norton, K. A., P. L. Rice, and L. E. Vogler, The use of angular distance in estimating transmission loss and fading range for propagation through a turbulent atmosphere over irregular terrain, Proc. IRE 43, 1488-1526 (Oct. 1955).

Rice, P. L., A. G. Longley, and K. A. Norton, Prediction of the cumulative distribution with time of ground wave and tropospheric wave transmission loss; Part I-The prediction formula, NBS Tech. Note No. 15 (July 1959).

Schelleng, J. C., C. R. Burrows and E. B. Ferrell, Ultra shortwave propagation, Proc. IRE 21, 427-463 (Mar. 1933).

Wait, J. R., and A. M. Conda, Diffraction of electromagnetic waves by smooth obstacles for grazing angles, J. Research NBS 63D (Radio Prop), No. 5, 181-197 (Sep.-Oct. 1959).

(Paper 65D5-149) 